Hypotheses

\title{
Extending the Repertoire of Structures in DNA Nanotechnology
}

\author{
Clive Delmonte \\ Open University, Clarendon Park, Nottingham NG5 1AH, UK
}

Article history

Received: 23-02-2015

Revised: $15-04-2015$

Accepted: 29-07-2015

E-mail: clivedelmonte@gmail.com

\section{Introduction}

This paper seeks to identify and address the many experimental problems to which the DNA double helix model seems to offer no solution such as the inevitable topological complexity of the DNA octahedron (Zahid et al., 2013). Thus the body of DNA studies in nanotechnology can be strengthened and fresh approaches to potential developments in DNA nanotechnology can be identified.

This work is set out in sections. Many sketches and diagrams are included to make the paper clear. The ubiquitous and iconic DNA double helix model (Watson and Crick, 1953; Crick and Watson, 1954)

\begin{abstract}
DNA nanotechnology remains an active area of research and advances have been reviewed recently. DNA nanotechnology seeks to deper and an at small molecule scale. Other techniques in biophysics and biochemistry do not need to address the issue of the true structure of the nucleic acids at an atomic level but, rather, at a As in genetics and in immonology, for example. Accordingly, DNA nanotechnology is perhaps uniquely dependent upon exact clarity in the secondary and tertiary structures of the nucleic acids, as wer achieved. Challenges include expanding the use of DNA in medicine, and the construction of detectors with higher sensitivity for biological and chemical settings. Though increasingly complex arche been constructed, novel approaches to a greater rôle in biological computation and data storage remain important goals. Here a repertoire of structures for DNA at an atomic level is described which offers a conjecture with which to move forward. The DNA double helix model faces many problems which have become apparent in the 62 years of research in molecular biology that have elapsed since it was formulated by Watson and Crick in 1953. Experimental evidence is set out seeking to show that the only truly side-by-side alternative, the paranemic model, accounts better for the wide range of phenomena otherwise engage in a repertoire of structural options denied to the DNA double helix model. Without the requirement to postulate unwinding of the DNA strands, the nucleotide base sequence is immediately accessible to complementary DNA sequences to promote rapid detection of specific molecules in biological and medical settings. Rapid switching between Watson-Crick and Hoogsteen base pairing and four-stranded structures can allow greater complexity in the construction of
\end{abstract}

Keywords: DNA Computation, DNA Double Helix, DNA Nanotechnology, Paranemic DNA Helix, Lőwdin Pairing of Base Pairs, Z-DNA 
aqueous solution or suspension of DNA or of an oligodeoxyribonucleotide to effect strand separation in the absence of any and all proteins and enzymes.

However, heat applied in this way is a scalar quantity, as it has magnitude but no preferred direction, while the unwinding process requires an axial torque. Torque, even if it could be applied to an isolated, solitary molecule, is a vector as it does have direction (and magnitude). How a scalar heat input can be transformed into a vector force in a solution has never been explained.

It has long been known that organic solvents, and even aqueous urea, will rapidly denature (unwind) the DNA double helix (Alexander and Stacey, 1957; Herskovits et al., 1961; Geiduschek and Herskovits, 1961; Herskovits, 1962; Porschke, 1977) at constant temperature in the total absence of any and all proteins but again the mechanism has never been explained.

Furthermore, such unwinding changes would require an overall change in angular momentum contravening the well-established Law of Conservation of Momentum.

In theorizing on the disruption and reformation of secondary structures in DNA, intertwined 'rope' models such as the W-C double helix thus encounter severe difficulties with the conservation of angular momentum, one of the best-established laws of science. This is perhaps the most neglected doubt about what have become standard models for DNA secondary structures. Side-By-Side, including paranemic models escape the winding/unwinding problem because they do not have to wind or unwind as their strands are not ravelled.

No source has been suggested for this unwinding angular momentum. If some chiral process in forming the new polymer chains is to transfer angular momentum from other molecule(s) to the unravelling strands, this warrants a detailed explanation.

The reverse process of denaturing duplex DNA, namely so-called "renaturation", attracts similar reservations, but in reverse.

Another problem for the double helix model is that, whether right or left-handed, each hand exists in principle in two stereoisomers, a point first made by Hopkins (1981). Neither Watson nor Crick had identified this aspect of their model, so neither was impelled to explain how they had made their particular choice of stereoisomer.

While the existence of two stereoisomers might seem an arcane and unimportant feature of DNA structure, its implications can be important and are unexplored. For instance, the particular stereoisomers of DNA in the different biological kingdoms, extending to viruses, bacteria, fungi, yeasts and mammals have not been identified and compared. When gene inserts are considered in genetic manipulation, it is implicitly assumed that the insert DNA is of the same stereoisomer (and handedness) as the host DNA. However, this assumption is untested. So it is possible that the gene insert has a different stereoisomer from that of the intended host DNA. This could explain why some gene inserts are readily identified and are then rapidly excised by the intended host.

Though the DNA cube, and DNA octahedron (Zahid et al., 2013) for example, are well known and have been drawn in detail, the evident complexity of such molecules, and other, comparable constructs using the double helix, seems to constitute a formidable obstacle to attempts to further develop such concepts and to widen the use of such DNA constructs in medicine, computing and in nanorobotics.

The so-called side-by-side DNA structures avoid the unwinding problem altogether, though whether right or left-handed, they too exist as two possible stereoisomers each (Hopkins, 1981).

Following the Principle of Occam's Razor, namely that entities [like the structure of duplex DNA] must not be multiplied in complexity beyond necessity or must entail the fewest assumptions, the simplest of these structures has been designated the Paranemic Helix which is the only truly side-by-side structure (Fig. 1).

\section{Materials and Methods}

This study consists of a close scrutiny of disparate experimental results for the structure of duplex DNA reported across many journals over the previous 60 years. Evidence is brought together to demonstrate that the uncritical acceptance of the double helical structure for duplex DNA damages the coherence of DNA nanotechnology. The evidence is better understood by applying the paranemic model of duplex DNA to effect a resolution of the many unresolved conflicts in the reported experimental observations.

\section{The Paranemic DNA Duplex}

It has been considered that the DNA paranemic duplex structure, Fig. 1, is unstable or non-existent as it has been asserted that the strands would drift apart in an aqueous medium. There are many difficulties with such a view. First, a DNA side-by-side structure has been observed experimentally by $\mathrm{Wu} \& \mathrm{Wu}$ and has been reported (Wu and $\mathrm{Wu}, 1996)$.

Second, no experimental evidence has been advanced to support the assertion that all paranemic DNA structures should be discounted. The contention of (Crick et al., 1979) that topology eliminated all side-byside structures is flawed and did not consider the structure set out in Fig. 1, nor did it fully explore the implications of the Rodley model (Rodley et al., 1976; Bates et al., 1980; Rodley et al., 1984; Rodley, 1995).

Third, since 1953, and following the rapid growth of researches into the biophysics and molecular biology of DNA, a growing body of experimental results has become difficult to interpret using the DNA double helical model. These results have been summarised in outline (Delmonte and Mann, 2003; Gautham, 2004) and have been reviewed in detail (Delmonte, 1991). 


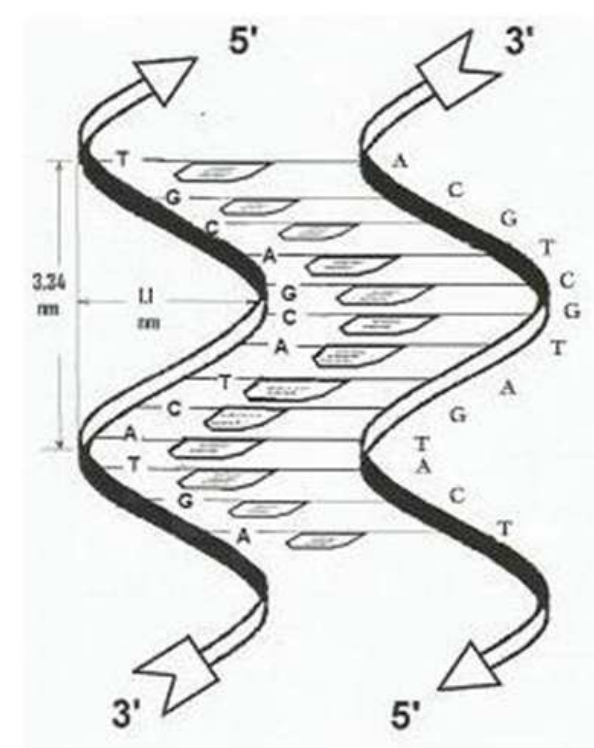

Fig. 1. A view of a true side-by-side (paranemic) model for B-form duplex dna looking towards the "front" face

Moreover, in 1953, James and Mazia (1953) found that $1 \mathrm{mg}$ of dry calf thymus DNA could be spread in a monolayer to $0.28 \mathrm{~m}^{2}$ in a Langmuir-Blodgett trough. The cross-section of duplex DNA was found to be 1.17 $\mathrm{nm} \times 2.16 \mathrm{~nm}$ with each dimension determined using a different technique (Delmonte, 1991 (Appendix 1), (James and Mazia, 1953). This oval cross-section eliminated the possibility of the double helical structure as this model has a circular section. It seems that Crick $\&$ Watson were never aware of this result.

The open structural model in Fig. 1 lends itself naturally to a display of its nucleotide sequence and offers a researcher an uncomplicated account of how sequence-specific proteins might interact with it. Moreover, DNA and RNA probes can readily find their target DNA sequences. Using the double helical model, the duplex must unwind at least a short length, repeatedly if necessary, in order to interact with any sequence probe as it approaches, in a manner never fully explained. Indeed, diagrams in textbooks generally represent the double helix as a ladder structure in such interactions.

Finally, a substantial body of literature supports the proposition that the paranemic structure of Fig. 1 explains better all the known experimental results for DNA in biophysics and molecular biology than does the double helix (Delmonte, 1991).

The paranemic duplex, like the double helix, and whether right or left-handed, can exist as two stereoisomers and the sketch in Fig. 1 is informed by this knowledge. The choice of stereoisomer has been determined from scrutiny of nucleosomal cutting sites by deoxyribonuclease 1 on DNA and the overhang of the resulting fragments (Delmonte, 1991).
Figure 1, B form DNA, was drawn by Dr K. Biegeleisen and is used here with permission.

\section{The Pairing of Watson-Crick Base Pairs ("Lőwdin Tetrads")}

The paranemic model offers a degree of complexity in its structural interactions which is unavailable to the double helix.

In 1963 Lőwdin described the pairing of WatsonCrick base pairs (Löwdin, 1963) and in 1991 this approach was extended when the pairing of Hoogsteen base pairs (Delmonte, 1991) was described. The important feature of these suggestions is that a construct exists which formalises the manner in which a pair of paranemic duplexes can not only easily recognise the same, or closely similar, base sequence in an adjacent duplex, but offers the researcher an explanation of how a DNA or RNA probe can recognise and bind to its target sequence.

It is evident that the unpaired electric charges in Hoogsteen base pairs and tetrads will change the electrical properties of these pairings relative to the Watson-Crick equivalents. In addition, the optical dichroism and cross-section of the Hoogsteen tetrad will change relative to the Watson-Crick tetrad. Moreover, it is evident that a Watson-Crick base pair is convertible into a Hoogsteen base pair via the rotation through $180^{\circ}$ of the glycosidic bond (Delmonte, 1991 (Appendix 3, Fig. A, B and C)).

Figures $2 \mathrm{~A}$ to $2 \mathrm{D}$ recapitulate the classical Watson-Crick and Hoogsteen base pairing and the pairing of these base pairs as "tetrads" after Löwdin (Löwdin, 1963), this author (Delmonte, 1991) and Hopkins (1986).

Such structures are impossible using the WatsonCrick double helix since its base sequence is substantially hidden within its helical turns. A double helix can only reliably recognise the same sequence in a neighbour by postulating at least a partial unwinding of one or more helical turns simultaneously at a time and at a place down the sequence which coincides with that same, or closely similar sequence in its near neighbour using an unknown mechanism to produce an implausible four-stranded (but double-helical) outcome.

A so-called Holliday junction as the postulated result of a four-stranded construct, has not been recorded at single strand resolution. Neither electron micrographs, nor AFM nor STM scans, allow a clear distinction to be made at present between the double helix and paranemic DNA in a Holliday Junction.

A four-stranded, Lőwdin intermediate has been used by Hopkins to account for his experimental results (Hopkins, 1986). 


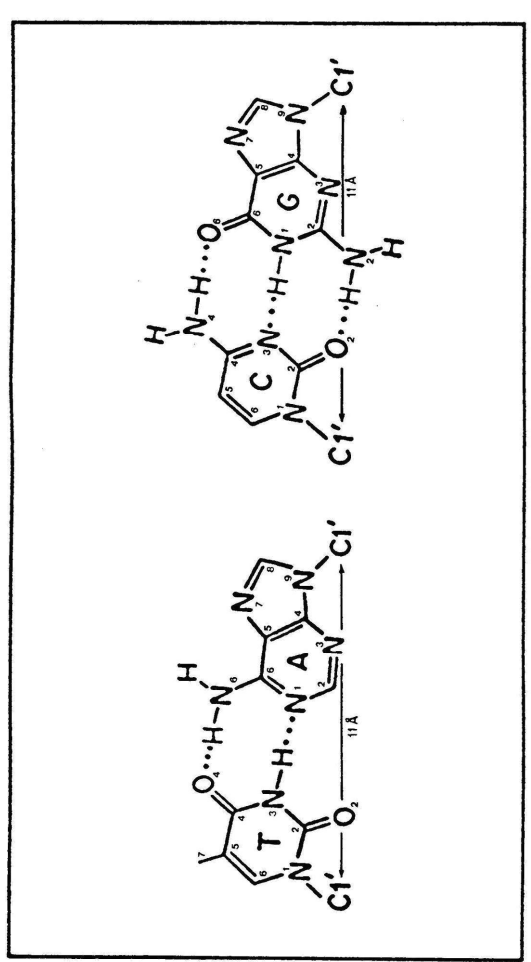

(a)
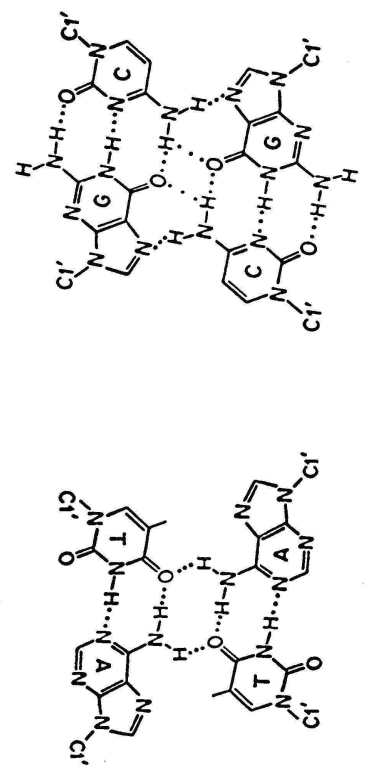

(c)

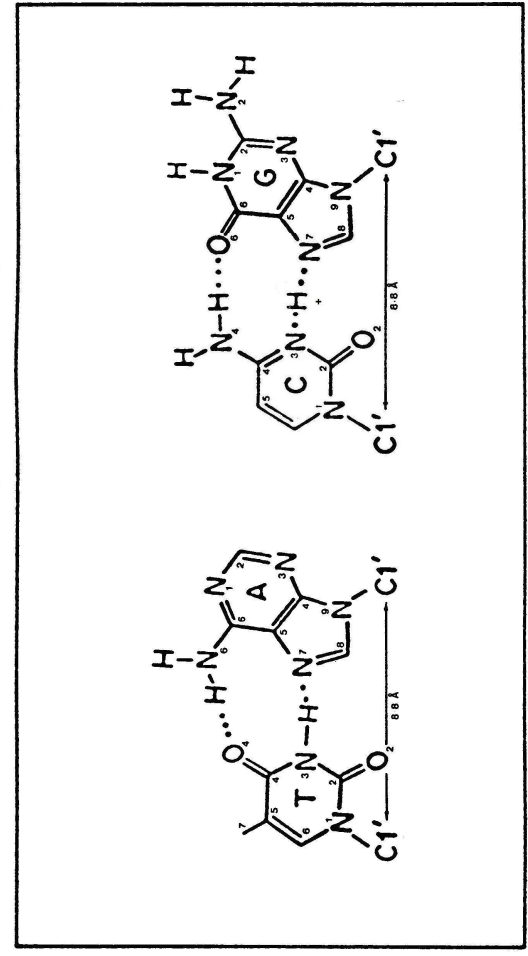

(b)

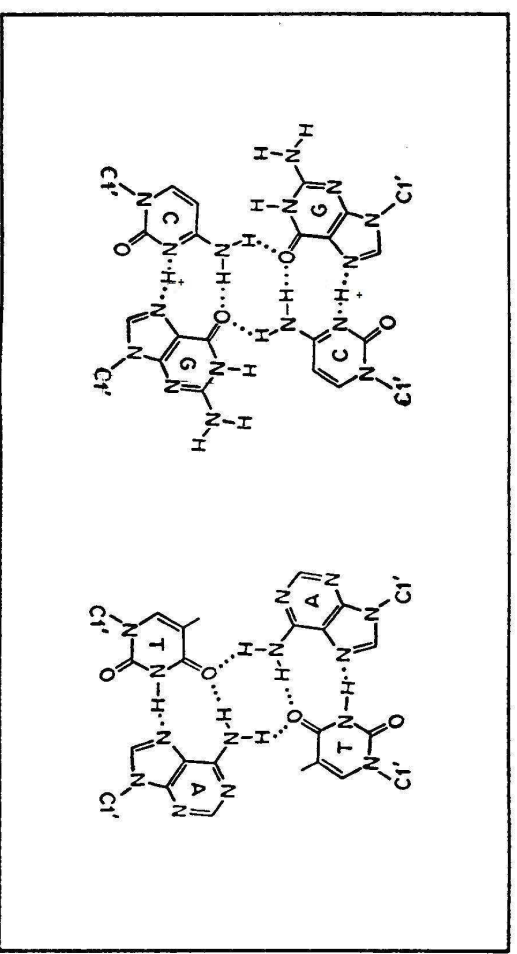

(d)

Fig. 2. Sketches of the base pairs (2a and $2 b$ ) and of the pairing of base pairs (c and d) entitled the Löwdin tetrads (a) WatsonCrick nucleotide pairing (b) Hoogsteen nucleotide pairing (It is of the greatest importance in terms of the B-Z transition to note that Hoogsteen base pairs are related to Watson-Crick base pairs merely by a rotation of $\pm 180^{\circ}$ about the glycosidic band of the purine) (c) the unique pairing of Watson-Crick nucleotide pairs as Löwdin tetrads (d) the unique pairing of Hoogsteen nucleotide pairs Lőwdin in tetrads 


\section{The Use of Z-DNA in Nano Structural Studies}

Z-DNA has been explored as another aspect of the repertoire of DNA structures which could allow access to fresh nanostructures, for example (Corradini et al., 2001). The actual handedness of Z-DNA has been reviewed in detail (Delmonte, 2007).

Of course, using crystallography, Z-DNA has been claimed as left-handed, that is, Z-DNA enjoys a helical handedness opposite to that of the B form.

Z-DNA crystallographic studies have been reported by Rich's group (Crawford et al., 1980; Rich et al., 1984). Hopkins (1981) showed that, even for a double helix, whether right-or left-handed, there would be two possible stereoisomers in each helical hand. The ZDNA researchers made no reference to this and did not discuss how they came to prefer one isomer rather than the other. The alternative stereoisomer for ZDNA was investigated using NMR much later by (Uesugi et al., 1988).

The raw crystallographic diffraction data from Rich's group were never lodged with the Protein Data Bank (Berman et al., 2000) or the Nucleic Acid Database (Berman et al., 1992).

Other researchers (Malinina et al., 1998), however, did lodge their raw diffraction data and structure factors derived from X-ray diffraction from crystals of d-CGCGCG. Their Z-DNA structure factor file, 392D, defines a supercell, that is, their chosen unit cell is larger than the crystallographic data requires. This choice of unit cell size is not solely crystallographic but is informed by the prior acceptance that the expected structural outcome is a double helix. The smaller unit cell would not accommodate a double helix. As a supercell, other structural solutions become possible utilizing a smaller unit cell.

One interesting philosophical problem arises at this point. If unit cells of two different dimensions but having the same shape can give rise to the same diffraction pattern, should the structural solution be able to satisfy both unit cell sizes? This problem apparently has not been addressed in the biopolymer or oligodeoxy-ribonucleotide crystallographic literature, but it is very important.

Another complication with oligodeoxyribonucleotide crystallography is that the structural refinement process frequently makes use of the computational software Nucleic Acid Least Squares, NUCLSQ. For example, researchers report (Sadasivan et al., 1994) that their refinement of the structure factors of a $\mathrm{Z}$ form hexamer was carried out using the algorithm NUCLSQ. This contains within it the sub-routine NAHELIX (Malinina et al., 1998) which contains a model double helix. Therefore a double helical computational outcome is the only possibility.

In addition, and not recorded by (Crawford et al., 1980; Rich et al., 1984), according to Miller and his colleagues (Miller et al., 1983), the $\mathrm{B} \rightarrow \mathrm{Z}$ transition of poly $\left(\mathrm{d}\left(\mathrm{G}-{ }^{\mathrm{m} 5} \mathrm{C}\right)\right)_{2}$ is facilitated by an order of magnitude when the $\mathrm{B}$ form has been already wound onto nucleosomal histones as a superhelix, constrained by its close contact with the nucleosomal histones, compared with the rate for the $\mathrm{B} \rightarrow \mathrm{Z}$ transition for the polymer freely suspended in solution.

This experimental observation poses a severe test for the proposition that Z-DNA has a different helical sense from B-DNA.

An explanation of this phenomenon has been offered (Delmonte, 1991; 2007).

If a change in helical sense is involved here, it is important that an explanation be generally accepted as to how it could be an order of magnitude faster to form Z-DNA from B-DNA when the latter is wound around as a superhelix for 1.75 turns in direct contact with a solid histone surface compared to forming Z-DNA from B-DNA freely in solution.

There are many other difficulties with the two propositions that the $\mathrm{Z}$ form is, or contains a double helix and that it is left-handed (Delmonte, 2007; Delmonte, 2008).

A resolution of these aspects is summarized in Fig. 3.

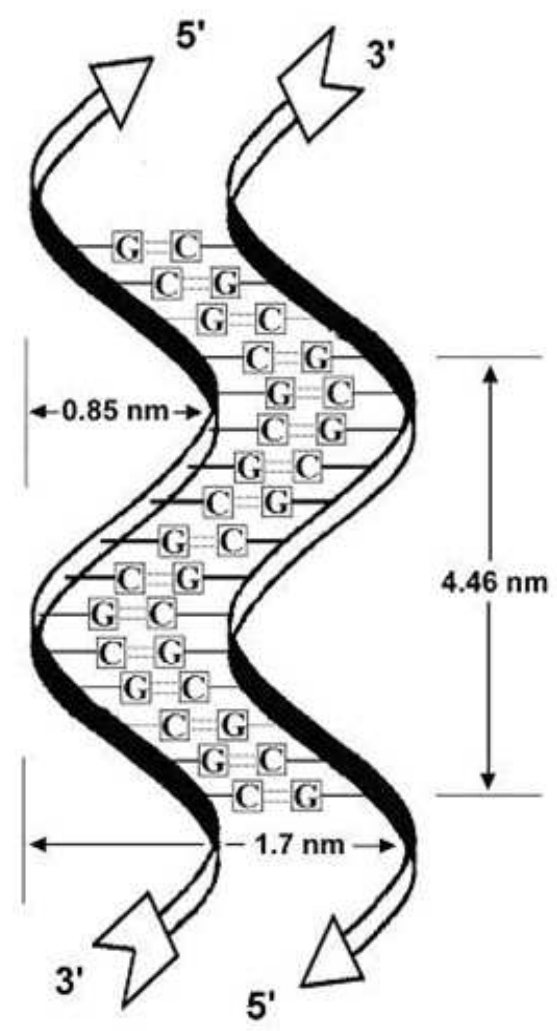

(4) Dr Ken Biegeleisen 2004

Fig. 3. Sketch of paranemic $Z$ form DNA (The equivalent stereoisomer as in the B form) Fig. 3 is published with permission 


\section{Aspects of the Paranemic Model}

In Fig. 1 it is evident that if one paranemic molecule is turned to face another, front to front, using any base sequence common to, or closely similar in both, tetrads can be formed over the whole length. One of the pair must move its crest and trough by $180^{\circ}$ (a half cycle) along the sequence but this geometric feature is labile along the sequence (Delmonte, 1991).

A further structural possibility offers itself. With a regular sequence down the two chains of one duplex the pair of chains can fold over into a hairpin, as a tetrad, without a second duplex being involved.

It may be possible to form a new type of nanowire by immersing a DNA duplex in a solution of divalent metal ions, washing off the excess, and then allowing a duplicate duplex to form a tetrad to seal in the metal ions lying in the core.

\section{Results}

Experimental data for both the double helix and paranemic DNA models can be compared. For example, Hoogsteen base pairs are related to Watson-Crick base pairs by a rotation of $180^{\circ}$ around the purine glycosidic bond, that is, two known states in a binary system. There are no known reports of rotation around the pyrimidine glycosidic bond. Therefore a suitable chromophore attached to a pyrimidine, especially at the prominent position 5, should show a modulation of optical properties as its purine partner rotates.

\section{Conclusion}

Use of the paranemic model allows new structural possibilities to be identified and new potential applications to be explored. The double-helical model for duplex DNA fails to offer the researcher insights which could allow fresh structural opportunities to be explored.

In Löwdin tetrads, base pairing can occur between either of the two adjacent DNA strands on each side of any particular strand as either Watson-Crick or Hoogsteen pairing is possible. This property would seem to suit binary transactions.

Apart from Löwdin tetrads, the paranemic model allows hairpin bends to form in a suitable, short repetitive nucleotide base sequence.

DNA nanotechnology seeks to deploy molecules at an atomic and small molecule scale, as illustrated, for example by (Zaera, 2013). Other techniques in biophysics and biochemistry do not need to address the issue of the true structure of the nucleic acids at an atomic level but, rather, at a macro-atomic level such as in genetics and in immunology, for example.

Accordingly, DNA nanotechnology is perhaps uniquely dependent upon exact clarity in the secondary and tertiary structures of the nucleic acids, as well as that can ever be achieved.

Such clarity will facilitate further researches aimed at new applications of DNA nanotechnology in medicine, computing and in engineering applications.

\section{Acknowledgment}

Permission from Dr. K. Biegeleisen to reproduce Figures 1 and 3.

\section{Funding Information}

This manuscript and its author have not benefitted from any financial assistance. The author is solely responsible for this work which is his alone (excepting the acknowledged assistance with drawing Figures 1 and 3).

\section{Ethics}

There are no known issues expected to arise from this hypothesis.

\section{References}

Alexander P. \& Stacey, K.A., 1957. The influence of concentration on dissociation of deoxyribose-nucleic acid by 4 molar urea. Experientia. 13, 307-308

Bates, R. H.T., McKinnon, G. A., Millane, R. P. \&Rodley, G. A., Revised Interpretations of The Available X-Ray Data For B-DNA, Pramana - $J$ Phys, 1980, 14, $233-252$

Berman, H. M., Westbrook, J., Feng, Z., Gilliland, G., Bhat, T. N., Weissig, H., Shindyalov, I. N. \& Bourne, P. E., The Protein Data Bank, Nucl Acids Res., 2000, 28, 235-242

Berman, H. M., Olson, W. K., Beveridge, D. L., Westbrook, J., Gelbin, A., Demeny, T., Hsieh, S.-H., Srinivasan, A. R. and Schneider, B., The Nucleic Acid Database: A Comprehensive Relational Database of Three-Dimensional Structures of Nucleic Acids, Biophys. J., 1992, 63, 751-759

Corradini, R., Tedeschi, T., Sforza, S., Green, M. M. \&Marchelli, R., Control of helical handedness in DNA and PNA Nanostructures, Methods Mol. Biol. 201174979 - 92

Crawford, J. L., Kolpak, F. J., Wang, A. H.-J., Quigley, G. J., van Boom, J., van der Marel, G. \& Rich, A., The Tetramer d(CpGpCpGp) Crystallises as a Lefthanded Double Helix;; Proc. Nat. Acad. Sci. (USA) 77 (1980) 4016-4020

Crick, F. H. C. and Watson, J. D., 1954: The Complementary Structure of Deoxyribonucleic Acid; Proc. Roy. Soc. (London) 223A: $80-96$

Crick, F. H. C., Wang, J. C. \& Bauer, W. R., Is DNA Really a Double Helix ?J. Mol. Biol., 129 (1979) 449-461 
Delbrück, M. 1979: In The Delbrück letters (cited by H. F. Judson, The Eighth Day of Creation, Penguin, 1979, p. 230, ISBN 0879694784)

Delmonte, C. S., 1991, A New Structural Molecular Biology; ISBN 095122760 2; (open access, please copy and paste the whole URL on one line into the browser) https://notahelix.net/delmonte/new struct mol biol. pdf and at http://clivedelmonte.wix.com/paranemicdna(under reconstruction)

Delmonte, C. S. \& Mann, L. R. B., Variety in DNA Secondary Structure, CurrSci, 2003, 85, 1564 1570; (open access); www.ias.ac.in; "; select 85; select Issue 11; from "Variety in DNA Secondary Structure (Reply), page 1564, Delmonte CS and Mann LRB; select pdf; select "Click here to download the article

Delmonte, C. S., The Handedness of Z-DNA, Journal of Medical \& Biological Sciences, Volume 1(1), 2007 (ISSN 1934-7189) (open access), www.scientificjournals.org/journals2007/articles/1020. $\underline{\mathrm{htm}}$

Delmonte, C. S., Reflections on the Secondary Structure of DNA and Other Biopolymers, J Chemistry, Biochemistry \& Molecular Biology, Volume 1 (1), 2009 (open access): www.scientificjournals.org; select archives; select Journal of Chemistry, Biochemistry and Molecular Biology; select Vol.1 (issue 1) 2009; select synopsis and download pdf; www.scientificjournals.org/journals2008/1408.pdf

Gautham, N. \& Reply from Delmonte, C. S. \& Mann, L. R. B., CurrSci 2004, 86,1352 - 1354; (open access); www.ias.ac.in ; under "Publications" select current science; select "Journal"; select "Volume"; select 86; select Issue 10; from "Variety in DNA Secondary Structure (Reply), page 1352, Delmonte C and Mann LRB, select pdf; select "Click here to download the article"

Geiduschek, E. P. \& Herskovits, T. T., Nonaqueous Solutions of DNA. Reversible \& Irreversible Denaturation in Methanol, Arch. Biochem. \&Biophys. 95 (1961) 114-129

Herskovits, T. T., Singer, S, J. \&Geiduschek, E.P., Nonaqueous Solutions of DNA. Denaturation in Methanol \& Ethanol, Arch. Biochem. \&Biophys. 94 (1961) 99-114

Herskovits, T. T., Nonaqueous Solutions of DNA. Factors Determining the Stability of the Helical Configuration in Solution; Arch. Biochem. \&Biophys. 97 (1962) 474-484

Hopkins, R. C., Deoxyribonucleic Acid Structure: A New Model; Science 211 (1981) 289 - 291

Hopkins, R. C., A Unique Four-stranded Model of a Homologous Recombination Intermediate; J. theor. Biol. 120 (1986) 215 - 222
James, T. W. \&Mazia, D., Surface Films of Desoxyribonucleic Acid; Biochim. Biophys. Acta10 (1953) 367 - 370

Löwdin, P.-O., Chapter in Electronic Aspects of Biochemistry, Editor B. Pullman; Academic Press (1963)

Malinina, L., Tereshko, V., Ivanova, E., Subirana, J. A., Zarytova V. \&Nekrasov, Y., Structural Variability and New Intermolecular Interactions of Z-DNA in Crystals of d(pCpGpCpGpCpG) (pdb 392D, zdf063, d-CGCGCG), Biophys. J., 1998, 74, 2482 - 2490

Miller, F. D., Rattner, J. B. \& van de Sande, J. H., Nucleosome-core Assembly on B \& Z Forms of Poly $\left(\mathrm{d}\left(\mathrm{G}-{ }^{\mathrm{m} 5} \mathrm{C}\right)\right)$, Cold Spring Harbor Symposia on Quantitative Biology, 1983, 47, 571-575

Porschke, D., Elementary steps of base recognition and helix-coil transitions in nucleic acids, Mol. Biol. Biochem. Biophys., 1977, 24, 191 - 218 and references therein

Rich, A., Nordheim, A. \& Wang, A. H.-J., The Chemistry \& Biology of left-handed Z-DNA, Ann. Rev. Biochem., 1984, 53, 791-846.

Rodley, G. A., Scobie, R. S., Bates, R. H. and Lewitt, R. M., A Possible Conformation for Double-Stranded Polynucleotides, Proc. Natl. Acad. Sci. USA, 1976, 73, 2959-2963

Rodley, G. A., Millane, R. P., McKinnon, G. A. \& Bates, R. H. T., Use of Axial Patterson in Assessment of Compatibility of Alternative B-DNA Structures with Fiber X-ray Data, J Roy Soc N Z, 1984, 14, 223 - 231

Rodley, G. A., Reconsideration of some results for linear and circular DNA, J. Biosc., 1995, 20, 245 - 257

Sadasivan, C., Karthe, P. \&Gautham, N., Space-Group Degeneracy in the Packing of a NonSelfComplementary Z-DNA Hexamer, ActaCryst., 1994, D50, 192 - 196

Uesugi, S., Lee, B. L., Ikehara, M., Fujii, S. \& Tomita, Hybrid Hexanucleotide Duplex Containing Cyclonucleotides and Deoxy-nucleotides: The d(TA) Segment Can Adopt a High Anti LeftHanded DoubleHelical Structure, Biochem., 1988, 27, 521 - 525

Watson, J. D. and Crick, F. H. C., 1953. Structure for Deoxyribose Nucleic Acid; Nature 171: 737 - 738

Wu, R. \& Wu, T. T., A Novel Intact Circular ds DNA Supercoil, Bull. Math. Biol., 1996, 58, 1171 - 1185

Zaera, F. Shape-Controlled Nanostructures in Heterogeneous Catalysis, ChemSusChem Reviews, Vol 6, 1797 - 1820, 2013 (Wiley)

Zahid, M. et al., DNA nanotechnology: a future perspective, Nanoscale Research Letters Vol 8, pp 119,2013 